\title{
Comparison of Growth, Yield, and Fruit Quality of Pot-planted Mango cv. Aikou Using Own-rooted Trees Propagated by Air Layering and Grafted Trees Propagated by Conventional Methods
}

\author{
Masahiko Fumuro ${ }^{1}$ \\ Experimental Farm, Kindai University, Yuasa, Arida-gun, Wakayama 643- \\ 0004, Japan
}

Additional index words. air layer propagation, dry weight, Mangifera indica, root system, T-R ratio

\begin{abstract}
To determine the potential of using own-rooted trees to lower tree height and delay the decline in tree vigor caused by root clogging, the growth, yield, and fruit quality of pot-planted 'Aikou' mango (Mangifera indica $L$.) trees propagated by air layering and grafting were observed for 8 years after planting. The trunk diameter of the own-rooted trees propagated by air layering (hereafter abbreviated as own-rooted trees) was significantly smaller than that of the grafted trees propagated by conventional methods (hereafter abbreviated as grafted trees), but there were no significant differences in the scion diameters of the grafted trees. Moreover, no significant differences were observed in leaf number or total length of green branches between the own-rooted and grafted trees during the final 3 years. The height of the own-rooted trees was significantly shorter than that of the grafted trees. Although no difference in the fresh or dry weight of the aboveground part and whole tree was observed between the own-rooted and grafted trees, the fresh and dry weights of the underground part of the own-rooted trees were significantly lower than those of the grafted trees. Furthermore, the T-R ratio (the weight of the aboveground part of the tree excluding the leaves/the weight of the underground part of the tree) of the own-rooted trees was significantly higher than that of the grafted trees. Overall, no significant differences in yield or fruit quality were observed between the two tree types, and the average yield per $1 \mathrm{~m}^{2}$ over 6 years was $2.9-3.1 \mathrm{~kg}$. These results indicate that it may be possible to lower tree height, delay the decline in tree vigor caused by root clogging, and prolong the life span of pot-planted trees by using ownrooted trees.
\end{abstract}

In Japan, mango (Mangifera indica L.) is generally cultivated in small greenhouses in which the height of the ridge is relatively low. Therefore, pot cultivation has been introduced for the purpose of lowering tree height and suppressing tree vigor (Yonemoto, 2008). However, pot cultivation in a greenhouse poses a problem in that the bearing fruit position tends to be higher than with conventional planting in the ground due to the height of the pot $(40-60 \mathrm{~cm})$. In addition, grafting in mango occurs at a high position of 30 to $50 \mathrm{~cm}$ above the ground (Yonemoto, 2008), which makes the rootstock longer and the fruit position higher.

In 'Irwin', the leading mango cultivar in Japan, because whole fruit colored red has high commercial value, lifting of the flower cluster and fruit is performed to improve

Received for publication 20 Feb. 2019. Accepted for publication 11 Apr. 2019.

${ }^{1}$ Corresponding author. E-mail: fumuro@nara. kindai.ac.jp. coloring via exposure to light. Furthermore, to harvest a fully ripened fruit on a tree, the fruit is covered with a bag-shaped net and hung with a string before harvest, so that the fruits do not fall as they mature. Thus, cultivating low tree heights, which bear fruit at low positions, is desirable.

The Aikou cultivar used in this study is a cross-breed between 'Chiin Hwang No. 1' as the seed parent and 'Irwin' as the pollen parent (Kindai University, 2008), and it is the first mango cultivar bred in Japan. It is characterized by its red skin color, large fruit, and soft, juicy flesh. The introduction of 'Aikou' should lead to the expansion of production areas and increased consumption of mango fruit. However, 'Aikou' has strong tree vigor, so it is likely to be higher than 'Irwin'. Furthermore, this cultivar needs more exposure to light for coloring the peel than does 'Irwin'.

Another problem with pot cultivation is that the rootstock of mango rapidly enlarges, so the interior of the pot tends to become clogged with age. The rootstocks that have been used in Japan are a vigorous Taiwan native strain, and trees grafted onto these rootstocks have strong vigor (Yonemoto, 2008). The underground part also has strong vigor, and enlargement of the underground part proceeds rapidly, such that the pots clog. Tree vigor declines when the roots become clogged, which decreases yield and fruit quality and can lead to death.

Because own-rooted trees have no rootstocks, the primary scaffold branches can be trained at a position closer to the ground, and lower tree height is thus expected. In addition, as own-rooted trees do not have an underground rootstock part to enlarge, it is possible to delay the decline in tree vigor caused by root clogging, and the life span of the tree is thus expected to be prolonged.

This study compared tree height, growth, yield, and fruit quality of own-rooted 'Aikou' mango trees propagated using an air layering with trees propagated using a conventional grafting method for 8 years after planting, to assess the practicality of using own-rooted trees for pot cultivation.

\section{Materials and Methods}

Nursery tree production and cultivation method

Production of own-rooted and grafted nursery trees. 'Aikou' trees planted in a two-span greenhouse (width: $9 \mathrm{~m}$, length: $54 \mathrm{~m}$, height: $4.3 \mathrm{~m}$, area: $972 \mathrm{~m}^{2}$ ) at the experimental farm of Kindai University (Yuasa, Wakayama Prefecture, Japan) were used.

Air layer propagation was performed on 18 May 2008 according to the method of Fumuro (2011b). On 22 July 2008, rooted branches (Fig. 1) were removed and planted in 1.3-L poly pots (diameter: $13.5 \mathrm{~cm}$, height: $11 \mathrm{~cm}$ ). On 4 Nov. 2009, the own-rooted nursery trees subjected to air layer propagation were transferred to $25-\mathrm{L}$ pots constructed of a nonwoven fabric (diameter: $32 \mathrm{~cm}$, height: $35 \mathrm{~cm}$ ) and filled with a mixture of mountain soil, perlite, compost, and vermiculite (volume ratio: 1:1:1:1).

The 'Aikou' scions were grafted onto 2year-old rootstocks (Taiwan native strain seedlings) planted in 8.5 -L poly pots (diameter: $24 \mathrm{~cm}$, height: $24 \mathrm{~cm}$ ) on 15 June 2009. The grafting position was an average of $24 \mathrm{~cm}$ above the ground. On 22 Oct. 2009, the

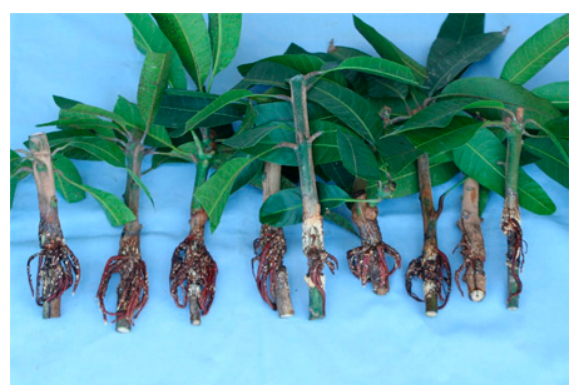

Fig. 1. Rooting of air-layered mango cv. Aikou (22 July 2008). 
plants were transferred to pots constructed of nonwoven fabric, as described previously.

Based on the age of the underground part, the age of both the own-rooted trees following air layer propagation and the grafted trees was 2 years, as of Dec. 2009. Ten own-rooted trees and nine grafted trees were used in this study.

Cultivation management. All pots were managed in a two-span greenhouse as described previously until Oct. 2012. The pots were arranged with 1.4-m spacing between rows, and pots were separated by $1.5 \mathrm{~m}$ within rows. In Nov. 2012, all pots were transferred to a smaller plastic greenhouse (width: $6 \mathrm{~m}$, length: $18 \mathrm{~m}$, height: $4 \mathrm{~m}$, area: $108 \mathrm{~m}^{2}$ ) and arranged with the same spacing between pots.

The greenhouse was heated from early December to ensure a minimum temperature of $6{ }^{\circ} \mathrm{C}$. This minimum temperature was increased gradually beginning in midFebruary and maintained at $18-20{ }^{\circ} \mathrm{C}$ during the flowering period. A fan was used for ventilation to ensure that the internal air temperature remained $<30^{\circ} \mathrm{C}$ until flowering and $<35{ }^{\circ} \mathrm{C}$ after flowering. Irrigation was controlled using an automatic timer. Approximately $50 \mathrm{~g}$ of slow-release fertilizer $(10 \mathrm{~N}-$ $10 \mathrm{P}-10 \mathrm{~K})$ was supplied to each tree five times per year. Approximately $50 \mathrm{~g}$ of organic fertilizer $(6 \mathrm{~N}-8 \mathrm{P}-4 \mathrm{~K})$ per pot was applied once per year. In total, there were 476 pots per $1000 \mathrm{~m}^{2}$ of land area and 15.7 , 16.2 , and $15.2 \mathrm{~kg}$ of nitrogen, phosphoric acid, and potassium, respectively, were supplied annually. Pruning began when the harvest was almost complete and ended in late September. Two to three scaffold branches per tree and an appropriate number of bearing shoots were set within a crown diameter of 1.3 to $1.4 \mathrm{~m}$. No pruning was carried out in 2016, as a dissecting survey was conducted in October. Diseases and pests were controlled according to conventional procedures.

Fruit management and harvesting. In June of every year, the fruit was thinned so that the leaf-fruit ratio (ratio of the number of leaves to fruit) was 60 . Each fruit was covered with a bag-shaped net before harvesting, and tree-ripe fruits that naturally dropped in the net were harvested from late July until early November every year.

\section{Measurements}

Tree growth. The stem diameter, number of leaves per tree, and the length of the green branch per tree were measured in late December every year from 2009 until 2015, and in Oct. 2016 (before the dissecting survey). Stem diameters were measured using calipers; the measurements were made $3 \mathrm{~cm}$ above the ground in the own-rooted trees, and $10 \mathrm{~cm}$ above the ground (trunk diameter) and $5 \mathrm{~cm}$ above the grafted part (scion diameter) in the grafted trees.

The length of the green branch with $<10 \%$ lignification was measured, and the total length of the green branch was calculated for each tree.
Tree height was measured from the bottom of the pot in Oct. 2016 at the time of the dissecting survey.

Fresh and dry weights of each organ. The dissecting survey was performed between 11 and 24 Oct. 2016. The trees were 9 years of age at the time of dissection. The different parts of the tree were categorized as follows: leaf, green branch, thick branch, trunk (including trunk derived from rootstock), fine roots $(<1 \mathrm{~mm}$ in diameter), and thick roots ( $\geq 1 \mathrm{~mm}$ in diameter, including the shoot-derived wood subjected to air layer propagation), and the fresh weight of each organ was measured.

Each organ sample was dried, and the percentage of dry matter was determined. The total dry weight of each organ was calculated by multiplying the percentage of dry matter by the total fresh weight of each organ.

The T-R ratio was calculated by dividing the weight of the aboveground part of trees excluding the leaves by the weight of the underground part of the trees. Forty leaves were randomly sampled from each tree, and leaf area was measured using an automatic leaf area meter (AAM-9; Hayashi Denko Co. Ltd., Tokyo, Japan). Total leaf area per tree was calculated by multiplying the average leaf area by the number of leaves per tree.

The trunks of each tree were cut using a saw at the position at which their diameters were measured. The contours were copied onto paper, and the cross-sectional area of each trunk was measured using the automatic leaf area meter, as described previously.

Flowering and harvest dates, and yield. According to the Okinawa Prefecture standard (Okinawa Prefecture, 2007), the flowering date was defined as the day when $50 \%$ of the flowers bloomed in $80 \%$ of the flower clusters.

Harvested fruit naturally dropped in the net every day. The weight of each fruit was measured, and the yield per tree and average fruit weight were calculated. The central day of the harvest period corresponded to the day when the number of harvested fruits reached $50 \%$ of the total.

Fruit quality. Approximately 10 to 20 fruits from both tree types, harvested from late August to mid-September at the peak of harvest every year, were used to measure fruit quality.

Peel color (Hunter's L-, a-, and b-values) was assessed using a color-difference meter (CR-400; Konica-Minolta, Tokyo, Japan) positioned centrally on the side of each fruit. Flesh firmness was determined using a Magness-Taylor-type fruit penetrometer with an 11.3-mm-diameter plunger (FT011; Effegi, Alfonsine, Italy) by removing a piece of peel $3 \mathrm{~cm}$ in diameter with a sharp knife. The maximum force generated when the plunger penetrated $7 \mathrm{~mm}$ into the flesh through the cut surface was recorded. Measurements were made on both sides of the fruit, and the average value was calculated.

In addition, flesh was collected from a central point on both sides of the fruit. Juice from the fruit was squeezed and filtered through gauze, and total soluble solids (TSS) and titratable acidity were determined. The TSS value was determined using a refractometer (PAL-1; Atago Co. Ltd., Tokyo, Japan), and titratable acidity was determined by the titration method with $0.1 \mathrm{~N} \mathrm{NaOH}$ to a phenolphthalein endpoint and converted to citric acid content.

\section{Statistical analysis}

The data obtained in this study excluding stem diameter were subjected to the $t$ test. A $P$ value $<0.05$ was considered significant. Differences in stem diameter were assessed with Tukey-Kramer's multiple range test.

\section{Results}

Tree height and growth. The height of the own-rooted trees $(2.00 \mathrm{~m})$ was significantly lower than that $(2.29 \mathrm{~m})$ of the grafted trees (Table 1). The trunk diameter of the ownrooted trees was significantly smaller than that of the grafted trees, but there was no significant difference between the trunk diameter of the own-rooted trees and the scion diameter of the grafted trees (Fig. 2A). At 9 years of age, the trunk diameter of the own-rooted and the grafted trees was 6.7 and $7.6 \mathrm{~cm}$, respectively, and the scion diameter of the grafted trees was $6.4 \mathrm{~cm}$. The trunk cross-sectional area of the own-rooted and grafted trees was 31.6 and $45.9 \mathrm{~cm}^{2}$, respectively (Table 1 ).

No significant difference in the total length of the green branches was observed between the tree types, excluding the first 3 years (Fig. 2B). The number of leaves per tree increased with age in both tree types, but no significant difference was detected (Fig. 2C). At 9 years of age, the leaf area of the ownrooted and grafted trees was 7.66 and $7.16 \mathrm{~m}^{2}$, respectively (Table 1).

Figure $3 \mathrm{~A}$ and $\mathrm{D}$ shows the tree shapes of the two tree types before the dissecting survey.

Fresh and dry weights of each organ. The fresh and dry weights of the green branches of the own-rooted trees were significantly

Table 1. Comparison of the total leaf area per tree, trunk cross-sectional area, and tree height of own-rooted and grafted 9-year-old mango cv. Aikou trees.

\begin{tabular}{|c|c|c|c|}
\hline Propagation method & $\frac{\text { Total leaf area }}{\left(\mathrm{m}^{2} / \text { tree }\right)}$ & $\frac{\text { Trunk cross-sectional area }}{\mathrm{z}}$ & $\frac{\text { Tree ht }}{(\mathrm{m})}$ \\
\hline Own-rooted & $7.66 \pm 1.34^{y}$ & $31.6 \pm 5.1$ & $2.00 \pm 0.30$ \\
\hline Grafted & $7.16 \pm 1.18$ & $45.9 \pm 5.0$ & $2.29 \pm 0.11$ \\
\hline Significance & NS & $* *$ & * \\
\hline
\end{tabular}

${ }^{\mathrm{z}}$ Trunk cross-sectional areas were measured at 3 and $10 \mathrm{~cm}$ above the ground in own-rooted and grafted trees, respectively.

${ }^{\mathrm{y}}$ Mean \pm standard deviation.

Ns, *, ** Nonsignificant difference or significant differences at $P=0.05$ or 0.01 , respectively $(t$ test $)$. 

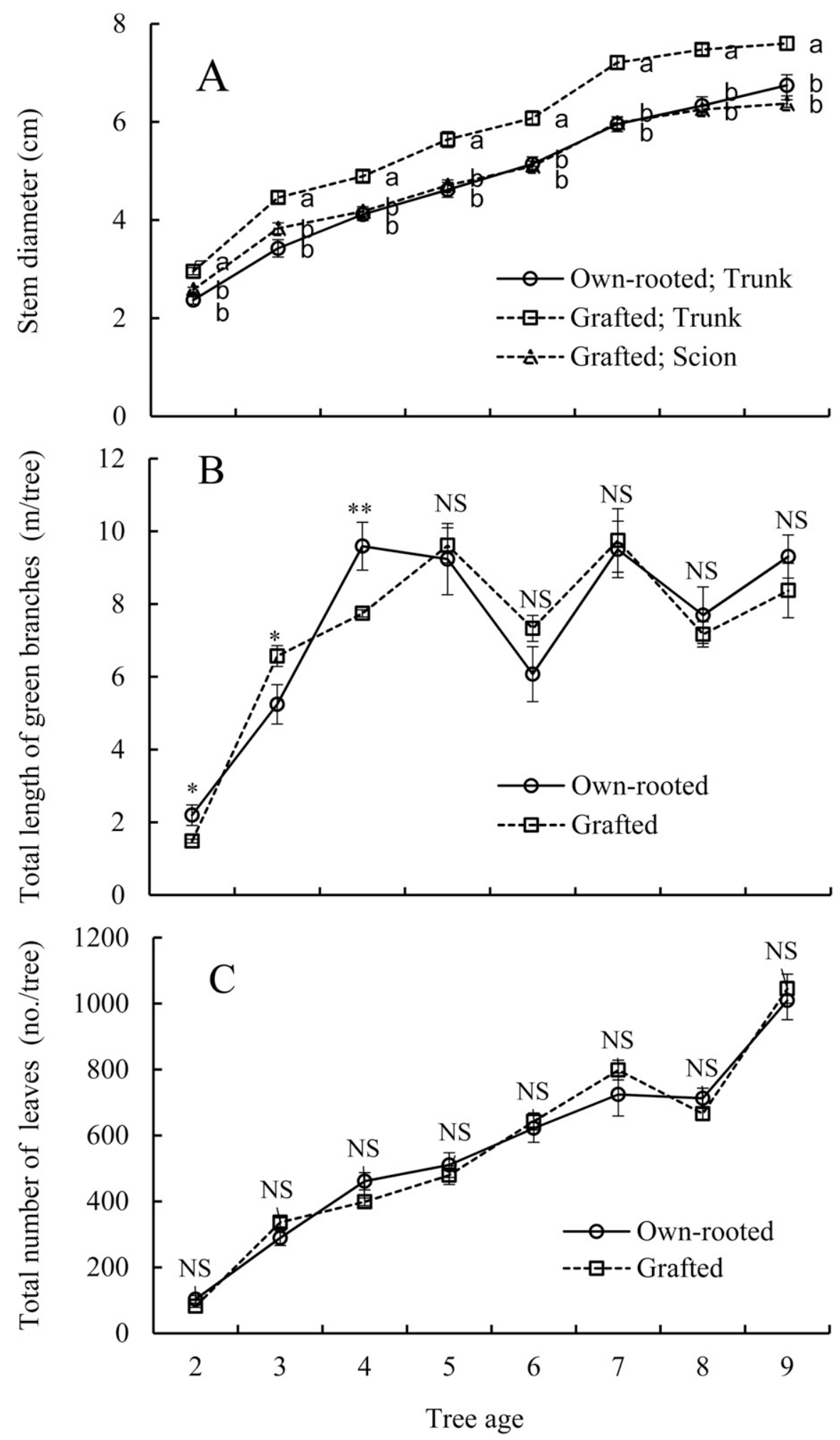

Fig. 2. Annual changes in the (A) stem diameter, $(\mathbf{B})$ total length of green branches, and $(\mathbf{C})$ total number of leaves of own-rooted and grafted mango cv. Aikou trees cultivated in pots. Vertical bars represent the standard error $[\mathrm{n}=10$ (own-rooted trees) and $\mathrm{n}=9$ (grafted trees)]. Values followed by the same letter do not differ significantly $(P<0.05$; Tukey-Kramer's multiple range test). Ns, *, and ** indicate nonsignificant difference and significant differences at $P=0.05$ and 0.01 , respectively ( $t$ test).

greater than those of the grafted trees; however, the fresh and dry weights of the trunk and thick root were significantly lower than those of the grafted trees (Table 2). No significant differences in the flesh or dry
On the other hand, the total fresh and dry weights of the underground part of the ownrooted trees were significantly lower than those of the grafted trees, being 1.92 and $3.03 \mathrm{~kg}$ fresh weight, and 0.63 and $1.06 \mathrm{~kg}$ dry weight, respectively (Table 2 ). No significant difference in the total weight of all trees was observed between the own-rooted and grafted trees, being 10.77 and $12.10 \mathrm{~kg}$ fresh weight, and 3.84 and $4.41 \mathrm{~kg}$ dry weight, respectively.

The fresh and dry weight $\mathrm{T}-\mathrm{R}$ ratios of the own-rooted trees were 3.42 and 3.55 , respectively, which were significantly higher than those of the grafted trees, of 2.22 and 2.18 , respectively (Table 2).

Figure $3 \mathrm{~B}$ and $\mathrm{E}$ show the state of the underground part of the own-rooted and grafted trees before the dissecting survey.

Flowering and harvest dates, yield, and fruit quality. The flowering date of the ownrooted trees was almost the same as that of the grafted trees, which was from early to late April (Table 3). The harvest period was from late July to mid-October, and the central day of the harvest period was from late August to mid-September for both tree types.

No significant difference in yield per tree was detected between the two tree types (Fig. 4A). The yield per tree of the ownrooted and the grafted trees was 3.3 and 3.6 $\mathrm{kg}$ at 4 years of age, 4.8 and $4.5 \mathrm{~kg}$ at 5 years, and 5.6 to $9.1 \mathrm{~kg}$ and 6.4 to $8.4 \mathrm{~kg}$ at 6 to 9 years, respectively. No significant difference in the number of fruits per tree was observed between the two tree types, except in 6-yearold trees (Fig. 4B). In addition, no significant difference was observed in average fruit weight, except in the 4-, 6-, and 9-year-old trees; the average fruit weight was 600 to $650 \mathrm{~g}$ in both tree types.

Figure $3 \mathrm{C}$ and $\mathrm{F}$ shows the state of fruiting in the own-rooted and grafted trees.

No significant difference in fruit quality was observed between the two tree types (Table 4). Throughout 6 years, the L-value was 34.5 to 39.6 , the a-value was 8.9 to 18.8 , and the b-value was 10.1 to 15.1 in both tree types. Flesh firmness was 7.1 to $8.3 \mathrm{~N} \cdot \mathrm{cm}^{-2}$, the soluble solids content was $15.2 \%$ to $17.1 \%$, and the citric acid content was $0.15 \%$ to $0.20 \%$ in both tree types.

\section{Discussion}

Effects of using own-rooted trees on low tree height. The own-rooted trees were $\approx 0.3 \mathrm{~m}$ lower in height than the grafted trees (Table 1), suggesting that using own-rooted trees may contribute to the establishment of a low tree height cultivation system for mango. As the primary scaffold branches of grafted trees were arranged on the scion grafted onto the rootstock, their positions were higher. In contrast, own-rooted trees are not grafted onto the rootstock, so it is possible to train them to grow closer to the ground such that, consequently, tree height is lower.

Primary scaffold branches have been trained to grow horizontally as close as possible to the ground, to increase work 
efficiency in mango (Yonemoto, 2008). Such a tree shape can be easily achieved with ownrooted trees without a rootstock.

Tree height can be lowered by pruning. However, if pruning is delayed because of a late harvest date, the shoot sprouted after pruning becomes weak and, as a result, stable, continuous fruit production is not maintained. 'Aikou' is a late-maturing cultivar; therefore, tight pruning is difficult when trying to lower tree height in the late harvest cultivation system adopted in this study. It is thought that further reductions in tree height can be realized by adopting an early maturing

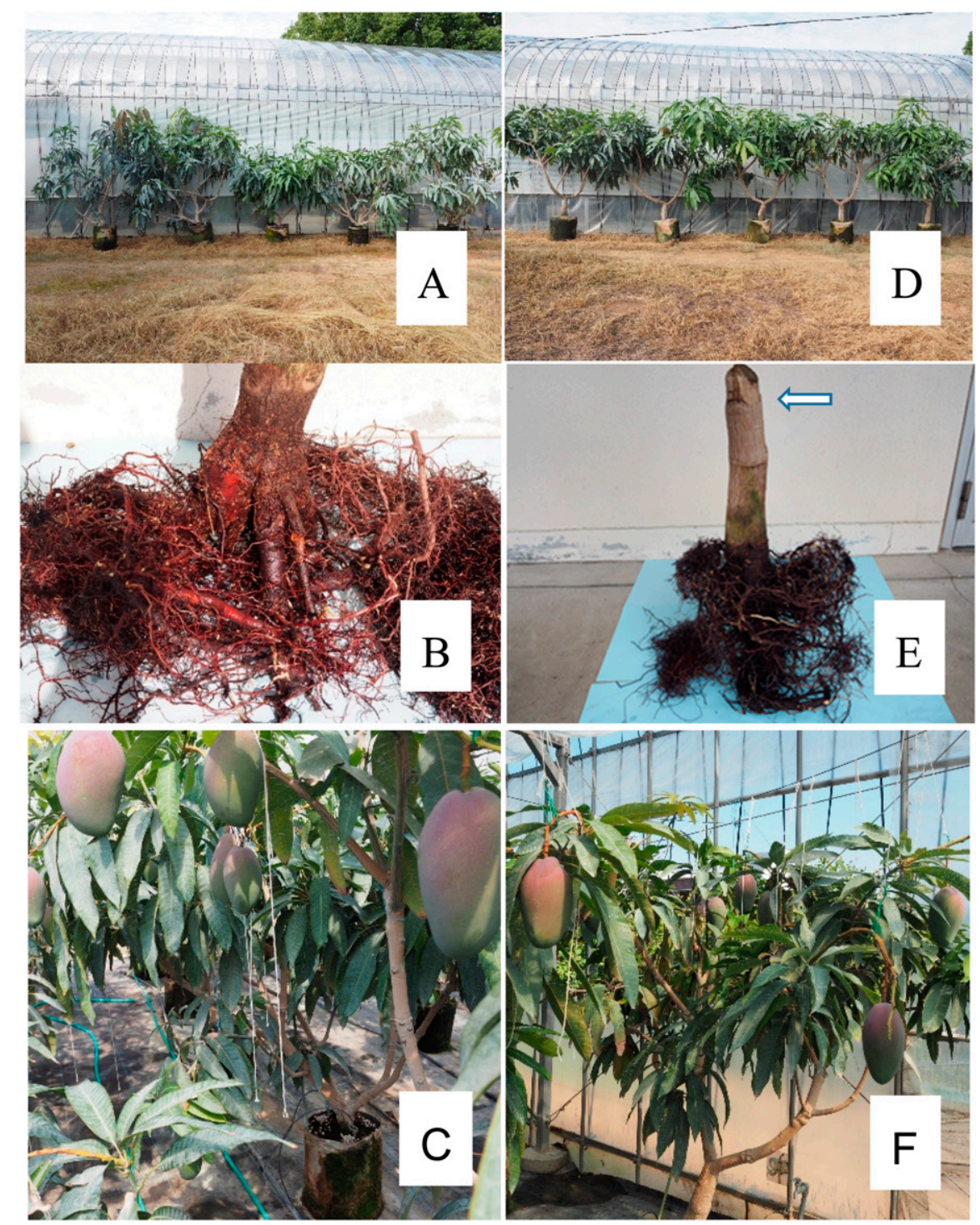

Fig. 3. Nine-year-old (A-C) own-rooted and (D-F) grafted mango cv. Aikou trees cultivated in pots. (A D) Whole view of own-rooted and grafted trees. (B, E) State of the underground parts of the ownrooted and grafted trees. White arrow indicates the grafted part. $(\mathbf{C}, \mathbf{F})$ State of fruiting in the ownrooted and grafted trees. cultivar or an early harvest cultivation system.

Effects of using own-rooted trees on the decline of tree vigor caused by root clogging. In this study, the decline in tree vigor caused by root clogging was not observed in either tree type for at least 8 years. Root clogging is thought to be caused by a small pot capacity relative to the amount of growth in the underground part; however, root clogging did not occur in this study, although the pot capacity used was smaller than that generally used. This suggests that the cultivation system in this study may have been a factor. Tamashiro et al. (2003) revealed that root growth of mango is remarkably suppressed by fruit bearing, and the roots grow accompanied by shoot elongation after harvesting. Because a late harvest cultivation system was adopted in this study, the amount of sunshine and temperature decreased gradually after the harvest date, suggesting that elongation and fulfillment of the shoot after pruning became insufficient; root growth decreased, and no root clogging occurred.

Growth of the underground part of trees is closely related to growth of the aboveground part (Fumuro, 1999; Fumuro et al., 1999). Therefore, it is necessary to comprehensively examine not only the underground part but also the aboveground part, when the aim is to reduce the effects of root clogging.

The dissecting survey revealed that the weight of the aboveground part was nearly equal between the tree types, but the weight of the underground part was significantly lower in the own-rooted trees than that in the grafted trees (Table 2). Consequently, the $\mathrm{T}-\mathrm{R}$ rate of the own-rooted trees was higher than that of the grafted trees. This finding suggests that the own-rooted trees do not need as many underground parts for tree growth and fruit production as the grafted trees.

In addition, the results suggest that using own-rooted trees delayed the root clogging caused by enlargement of the underground part during pot cultivation with limited soil capacity, which prolonged the life span of the pot-planted trees.

Although the weight of the thick root in the own-rooted trees was lower than that of the grafted trees (Table 2), Oya et al. (2015) reported that the dry weight of the underground part of own-rooted trees is lower than

Table 2. Comparison of the fresh and dry weights of own-rooted and grafted 9-year-old mango cv. Aikou trees.

\begin{tabular}{|c|c|c|c|c|c|c|c|c|c|c|c|}
\hline & \multirow[b]{2}{*}{ Propagation method } & \multicolumn{5}{|c|}{ Aboveground part $(\mathrm{kg})$} & \multicolumn{3}{|c|}{ Underground part (kg) } & \multirow{2}{*}{$\begin{array}{l}\text { Whole } \\
\text { tree }(\mathrm{kg})\end{array}$} & \multirow[b]{2}{*}{$\mathrm{T}-\mathrm{R}$ ratio" } \\
\hline & & Leaves & Green branch $^{z}$ & Thick branch & Trunk & Total & Fine $\operatorname{root}^{\mathrm{y}}$ & Thick root ${ }^{\mathrm{x}}$ & Total & & \\
\hline \multirow[t]{3}{*}{ Fresh weight } & Own-rooted & 2.57 & 0.62 & 5.12 & 0.54 & 8.85 & 0.43 & 1.49 & 1.92 & 10.77 & 3.42 \\
\hline & Grafted & 2.40 & 0.46 & 4.73 & 1.47 & 9.07 & 0.43 & 2.60 & 3.03 & 12.10 & 2.22 \\
\hline & Significance & NS & * & NS & $* * *$ & NS & NS & $* * *$ & $* * *$ & NS & $* * *$ \\
\hline \multirow[t]{3}{*}{ Dry weight } & Own-rooted & 1.12 & 0.18 & 1.72 & 0.19 & 3.22 & 0.11 & 0.52 & 0.63 & 3.84 & 3.55 \\
\hline & Grafted & 1.07 & 0.13 & 1.62 & 0.53 & 3.35 & 0.10 & 0.96 & 1.06 & 4.41 & 2.18 \\
\hline & Significance & NS & $* *$ & NS & $* * *$ & NS & NS & $* * *$ & $* * *$ & NS & $* * *$ \\
\hline
\end{tabular}

${ }^{\mathrm{z}}$ Branch with a ratio of lignification $<10 \%$.

${ }^{\mathrm{y}}$ Roots $<1 \mathrm{~mm}$ in diameter.

${ }^{\mathrm{x}}$ Roots $\geq 1 \mathrm{~mm}$ in diameter, including the shoot-derived wood subjected to air layer propagation in the own-rooted trees

${ }^{\mathrm{w}}$ Weight of the aboveground part of the tree, excluding leaves/weight of the underground part.

ns, ${ }^{*}, * *, * *$ Nonsignificant difference at $P=0.05$ or significant differences at $P=0.05,0.01$, or 0.001 , respectively ( $t$ test). 
Table 3. Flowering and harvest dates of own-rooted and grafted mango cv. Aikou trees.

\begin{tabular}{|c|c|c|c|c|}
\hline $\mathrm{Yr}$ & Propagation method & Flowering date d $^{\mathrm{z}}$ & Harvest period & Central day of harvest date ${ }^{y}$ \\
\hline \multirow[t]{2}{*}{2011} & Own-rooted & 20 Apr. & 24 Aug. -14 Oct. & 16 Sept. \\
\hline & Grafted & & 16 Aug.-8 Oct. & 12 Sept. \\
\hline \multirow[t]{2}{*}{2012} & Own-rooted & 23 Apr. & 11 Aug.-7 Oct. & 4 Sept. \\
\hline & Grafted & & 22 Aug. -9 Oct. & 9 Sept. \\
\hline \multirow[t]{2}{*}{2013} & Own-rooted & 11 Apr. & 6 Aug.-20 Sept. & 29 Aug. \\
\hline & Grafted & & 6 Aug.-19 Sept. & 28 Aug. \\
\hline \multirow[t]{2}{*}{2014} & Own-rooted & 9 Apr. & 5 Aug.-20 Sept. & 26 Aug. \\
\hline & Grafted & & 15 Aug.-25 Sept. & 29 Aug. \\
\hline \multirow[t]{2}{*}{2015} & Own-rooted & 25 Apr. & 28 Jul.-10 Oct. & 29 Aug. \\
\hline & Grafted & & 1 Aug.-30 Sept. & 26 Aug. \\
\hline \multirow[t]{2}{*}{2016} & Own-rooted & 7 Apr. & 5 Aug.-20 Sept. & 25 Aug. \\
\hline & Grafted & & 5 Aug.-26 Sept. & 25 Aug. \\
\hline
\end{tabular}

${ }^{\mathrm{z}}$ Date when $50 \%$ of the flowers bloomed in $80 \%$ of the flower clusters.

${ }^{\mathrm{y}}$ Date when the number of harvested fruits reached $50 \%$ of the total.
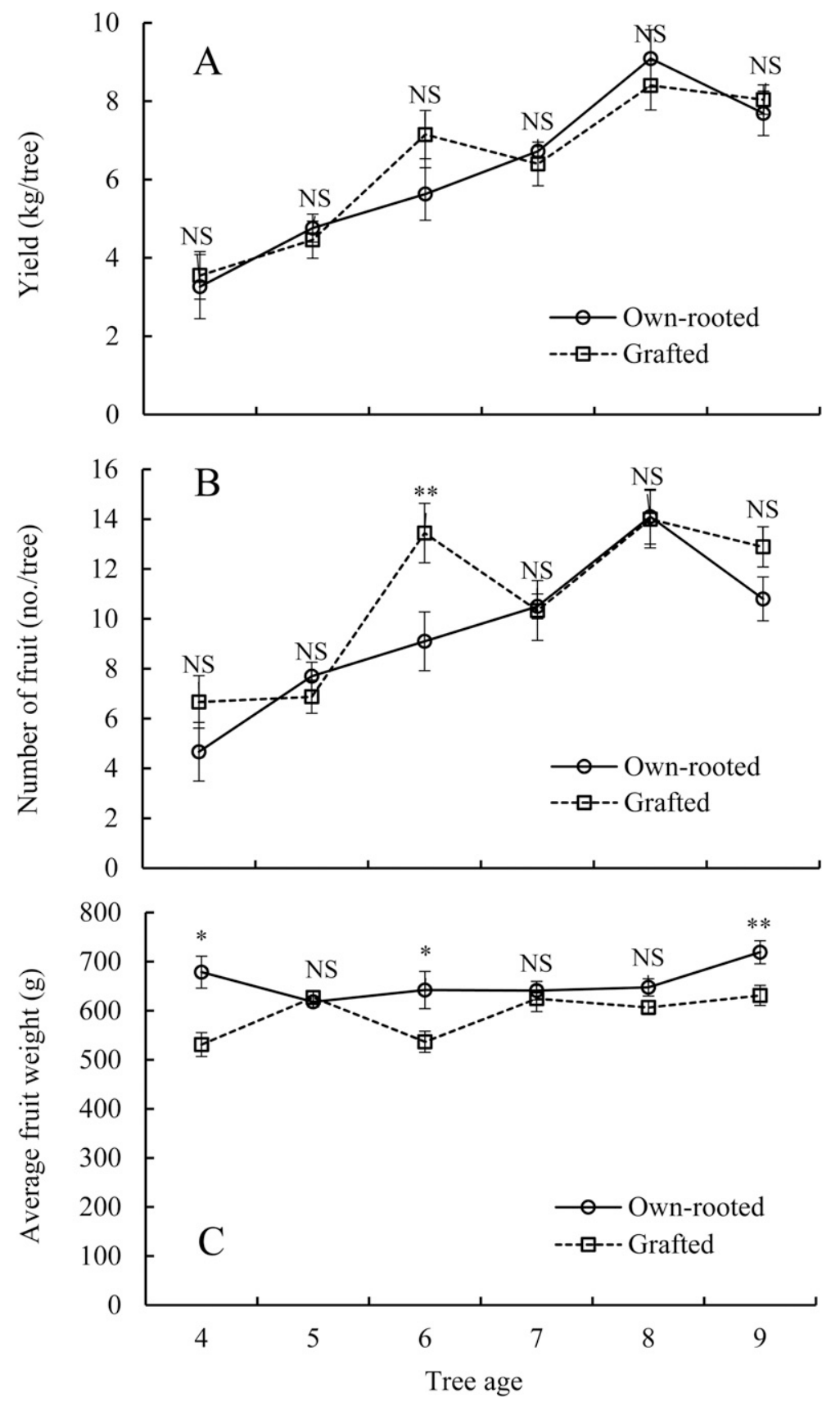

Fig. 4. Annual changes in (A) yield, (B) number of fruits, and (C) average fruit weight of own-rooted and grafted mango cv. Aikou trees cultivated in pots. Vertical bars represent the standard error $[\mathrm{n}=9$ (grafted trees) and $\mathrm{n}=10$ (own-rooted trees)]. Ns, *, and ** indicate nonsignificant difference and significant differences at $P=0.05$ and 0.01 , respectively $(t$ test). that of grafted Japanese pear trees. In grafted trees, the rootstock grows accompanied by relatively long main roots, and develops several thick roots. In the own-rooted trees, some of the roots resulting from air layering become thick roots (Fig. 3B, E; Table 2), with no main root. The weight of the thick root of the own-rooted trees became lower than that of the grafted trees.

Effects of using own-rooted trees on yield and fruit quality. Some research has compared yield and fruit quality of own-rooted trees obtained from vegetatively propagated and grafted trees (Couvillon, 1985; Oya et al., 2015; Tetsumura et al., 2010; Tous et al., 1997); however, no similar research has been conducted in mango.

In this study, the yield per tree increased with age, but the upper limit was reached after 8 years (Fig. 4A). Calculating the yield per unit land area from the planting density, the average value over 6 years was $2.9 \mathrm{~kg} \cdot \mathrm{m}^{-2}$ for the own-rooted trees and $3.1 \mathrm{~kg} \cdot \mathrm{m}^{-2}$ for the grafted trees. Fumuro (2011a) reported that the yield per tree of 'Aikou' cultivated at a leaf-fruit ratio of 60 was 2.5 and $4.6 \mathrm{~kg}$ for 3 - and 4-year-old trees, respectively ( 5 and 6 years of age in terms of root age); in this study, the values for the own-rooted trees were somewhat higher in 5-year-old trees but approximately the same in 6-year-old trees.

According to Fumuro (2011a) who studied 'Aikou' and 'Irwin', average fruit weight was greater with higher leaf-fruit ratio. The leaf-fruit ratio throughout the 6 years of this study was close to the setting value, but differed somewhat among years. The average fruit weight of both tree types was 600 to 650 g (Fig. 4C), and reached the typical fruit weight (600-700 g) of 'Aikou' (Fumuro, 2011a). The reason for the somewhat low average fruit weight of 6-year-old grafted trees seems to be the large number of fruit per tree and the low leaf-fruit ratio.

Although some variation in fruit quality was observed among years, there was no significant difference between the two tree types (Table 4), and the values were almost within the standard values for 'Aikou' (soluble solids content: $16 \%$ to $17 \%$, citric acid content: $0.15 \%$ to $0.20 \%$, flesh firmness: $7-8$ $\mathrm{N} \cdot \mathrm{cm}^{-2}$ ) (Fumuro, 2011a).

These results suggest that it is possible to lower tree height, delay the decline in tree vigor caused by root clogging, and prolong the life span of pot-planted trees by using own-rooted trees.

\section{Literature Cited}

Couvillon, G.A. 1985. Propagation and performance of inexpensive peach trees from cuttings for high density peach plantings. Acta Hort. $173: 271-282$

Fumuro, M. 1999. Interrelationship among tree growth parameters and dry weights of each organ in different aged Japanese persimmon (Diospyros kaki L. cv. Fuyu) trees (in Japanese with English abstract). J. Jpn. Soc. Hort. Sci. 68:355-363.

Fumuro, M., K. Ueda, and H. Okisima. 1999. Seasonal changes of dry matter production and assimilate partitioning in Japanese pear trees 
Table 4. Comparison of the fruit quality of own-rooted and grafted mango cv. Aikou trees.

\begin{tabular}{|c|c|c|c|c|c|c|c|}
\hline \multirow[b]{2}{*}{ Tree age } & \multirow{2}{*}{$\begin{array}{c}\text { Propagation } \\
\text { method }\end{array}$} & \multicolumn{3}{|c|}{ Peel color } & \multirow{2}{*}{$\frac{\text { Flesh firmness }}{\left(\mathrm{N} \cdot \mathrm{cm}^{-2}\right)}$} & \multirow{2}{*}{$\frac{\text { Total soluble solids }}{(\%)}$} & \multirow{2}{*}{$\frac{\text { Citric acid }}{(\%)}$} \\
\hline & & L-value & a-value & b-value & & & \\
\hline \multirow[t]{3}{*}{$\overline{4}$} & Own-rooted & 39.6 & 14.1 & 10.3 & 7.4 & 16.2 & 0.16 \\
\hline & Grafted & 36.3 & 12.5 & 10.4 & 8.3 & 15.2 & 0.15 \\
\hline & Significance & NS & NS & NS & NS & NS & NS \\
\hline \multirow[t]{3}{*}{5} & Own-rooted & 34.9 & 17.9 & 10.1 & 7.3 & 16.3 & 0.15 \\
\hline & Grafted & 35.2 & 16.0 & 12.5 & 7.4 & 16.4 & 0.15 \\
\hline & Significance & NS & NS & NS & NS & NS & NS \\
\hline \multirow[t]{3}{*}{6} & Own-rooted & 36.0 & 13.0 & 11.4 & 7.5 & 15.9 & 0.20 \\
\hline & Grafted & 38.9 & 18.8 & 12.8 & 7.3 & 16.3 & 0.18 \\
\hline & Significance & NS & NS & NS & NS & NS & NS \\
\hline \multirow[t]{3}{*}{7} & Own-rooted & 34.5 & 15.5 & 10.3 & 7.2 & 15.6 & 0.18 \\
\hline & Grafted & 35.6 & 16.6 & 11.4 & 7.1 & 16.2 & 0.17 \\
\hline & Significance & NS & NS & NS & NS & NS & NS \\
\hline \multirow[t]{3}{*}{8} & Own-rooted & 37.1 & 9.3 & 14.2 & 7.7 & 15.5 & 0.16 \\
\hline & Grafted & 36.7 & 9.6 & 13.7 & 7.8 & 15.4 & 0.16 \\
\hline & Significance & NS & NS & NS & NS & NS & NS \\
\hline \multirow[t]{3}{*}{9} & Own-rooted & 38.1 & 8.9 & 15.1 & 7.6 & 17.1 & 0.17 \\
\hline & Grafted & 37.8 & 9.6 & 14.2 & 7.6 & 17.0 & 0.16 \\
\hline & Significance & NS & NS & NS & NS & NS & NS \\
\hline
\end{tabular}

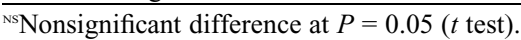

(Pyrus pyrifolia Nakai) cv. Kousui and Housui grown under film (in Japanese with English abstract). J. Jpn. Soc. Hort. Sci. 68:364-372.

Fumuro, M. 2011a. Effects of leaf-fruit ratio on yield and fruit quality in mango cv. Aikou under pot culture (in Japanese with English abstract). Hort. Res. (Japan). 10:383-388.

Fumuro, M. 2011b. Effect of several factors on rooting and cultivar differences in rooting abilities of air-layered mango (in Japanese with
English abstract). Hort. Res. (Japan). 10:451459.

Kindai University. 2008. Japan's Ministry of Agriculture, Forestry, and Fisheries cultivar registration. Registration number 16162 Kanpou. 4781. National printing bureau, Tokyo, Japan.

Okinawa Prefecture. 2007. Heisei-18-nendo Syubyotokusei-bunrui-chosa (in Japanese).

Oya, Y., Y. Ishioroshi, N. Negishi, N. Urata, and A. Kawaoka. 2015. Matter productivity of ownroot Japanese 'Kousui' (in Japanese). Hort. Res. (Japan). 14(suppl. 1):50.

Tamashiro, S., N. Matsuda, Y. Nagado, P. Wechvitan, and S. Shimabukuro. 2003. Relation between root growth and fruit load of mango 'Irwin' (in Japanese). Kyushu-nogyo-kenkyu 65:234.

Tetsumura, T., S. Haranoushiro, T. Marume, C. Torigoe, T. Omori, Y. Kurogi, Y. Uchida, and C. Honsho. 2010. Orchard growth, flowering and fruiting of 'Fuyu' and 'Hiratanenashi' Japanese persimmon trees grafted on potentially dwarfing rootstocks propagated by cutting. J. Jpn. Soc. Hort. Sci. 79:327-334.

Tous, J., A. Romero, J. Plana, M. Rovira, and F.J. Vargas. 1997. Performance of 'negret' hazelnut cultivar on several rootstocks. Acta Hort. 445:433-440.

Yonemoto, Y. 2008. Shin-tokusan-series Mango. Kanjukuka-seisan-no-zissai (in Japanese). Nobunkyo, Tokyo, Japan. 